\title{
Kajian Eksperimen Heat Exchahger Pada Heat Pump Menggunakan Refrijeran Hidrokarbon
}

\author{
Kusnandar, Gusniawan, Fajar Sentosa \\ Program Studi Teknik Pendingin dan Tata Udara, Politeknik Negeri Indramayu. \\ Alamat: Jl. Raya Lohbener Lama No. 08 Indramayu 45252 \\ Tlp/Fax. (0234) 5746464 \\ e-mail:battkus@yahoo.com, gusniawan@yahoo.com, fajarsentosa808@gmail.com
}

\begin{abstract}
Heat pump or usually known as pump energy is a device that can cooling and heating to be used, which functions as a cooling evaporator can be direct replace to heating as a function of the condenser using a reversing valve.. Using heat exchangers in the heat pump system is installed on the suction line and discharge line, so it will give the suction line temperature changes will be higher and discharge line temperatures will be lower, resulting in a greater cooling effect and lighter work of compression. The heat pump uses refrigerant type of hydrocarbon that is friendly to the environment, such as refrigerant $R-290$. From the results obtained research that the highest of Coefficient of Performance (COP) in the heat pump using heat exchangers is 4.8 and without using heat exchanger is 4.1. So value of COP of haet pump between using heat exchanger and withaout heat exchanger is 0.7. The highest efficiency obtained on the heat pump using heat exchangers is $90.3 \%$, and efficiency of heat pump without using heat exchanger is $78.95 \%$.
\end{abstract}

Keywords :heat Exchanger, Heat Pump, COP, Hydrocarbon, R-290

\begin{abstract}
Abstrak
Heat pump atau pompa kalor merupakan suatu alat yang bisa mendinginkan dan memanaskan, dimana fungsi evaporator sebagai pendinginan bisa diubah menjadi pemanasan sebagai fungsi kondensor dengan menggunakan reversing valve. Dengan menambahkan heat exchanger pada heat pumpyang dipasang pada suction line dan discharge line akan menghasilkan perubahan temperatur pada suction line lebih tinggi dan temperatur discharge line lebih rendah dibandingkan dengan sistem heat pump yang tidak menggunakan heat exchanger. Heat pump ini menggunakan refrijeran jenis hidrokarbon yang ramah terhadap lingkungan yaitu jenis refrijeran $R$-290. Dari hasil penelitian yang didapat bahwa nilai Coefficient Of Performance $($ COP) pada heat pump yang menggunakan heat exchanger adalah 4,8 sedangkan COP pada heat pumpyang tidak menggunakan heat exchanger sebesar 4,1.Sehingga selisih COP pada heat pump antara yang menggunakan heat exchanger dengan tanpa menggunakan heat exchangersebesar 0,7. Sedangkan efisiensi yang didapat pada heat pumpdengan menggunakan heat exchanger tertinggi sebesar 90,3\% sedangkan tanpa menggunakan heat exchanger tertinggi sebesar 78,95\%.
\end{abstract}

Kata kunci : Penukar Kalor, Pompa Kalor, COP, Hidrokarbon, R-290

\section{PENDAHULUAN}

Heat pump atau pompa kalor adalah suatu sistem yang memanfaatkan kalor yang dilepaskan di kondensor untuk pemanasan sehingga tidak dibuang ke lingkungan. memiliki komponen utama sama dengan sistem refrigerasi yaitu kompresor, kondensor,katup ekspansi (pipa kapiler) dan evaporatorsehingga sistem kerjanya pun tidak jauh beda dengan siklus refrigerasi kompresi uap pada umumnya. Untuk merubah fungsi pemanasan dan pendinginan diperlukan katup pembalik empat jalan (four way reversing valve)sehingga fungsi evaporator untuk menyerap kalor dari lingkungan akan berubah menjadi fungsi kondensor sebagai membuang kalor ke lingkungan [1]. Heat pump ini akan lebih efisien dan menghemat penggunaan energi maka diperlukanheat exchangerkarena berfungsi untuk membuat sistem pemanasan atau pendinginan pada heat pump menjadi lebih cepat [2]. Sehingga dengan penambahan heat exchanger ini diharapkan mampu mengurangi input daya yang besar dalam sebuah system heat pump.

Pada dasarnya sistem mesin pendingin (refrigerator) adalah juga merupakan suatu sistem heat pump, dimana kalor/energi termal dipindahkan dari suatu daerah ke daerah lain. Perbedaan mesin pendingin dengan pompa kalor hanya pada nilai gunanya. Dimana suatu sistem refrigerasi adalah untuk mendapatkan efek pendinginan yang maksimal yang didapatkan dari evaporator yang menyerap temperatur disekitarnya pada suatu daerah/ruangan, sedangkan nilai performansi dari suatu heat pump 
adalah disamping untuk mendapatkan efek pendinginan juga efek pemanasan oleh unit kondensor. Penggunaan heat pump masih di Indonesia masih belum banyak dimanfaatkan akan tetapi dimungkinkan untuk pengembangannya kedepan.

\section{TINJAUAN PUSTAKA}

Sistem refrigerasi kompresi uap pada umumnya menggunakan empat komponen utama yang bekerja bersama-sama yaitu kompresor, kondensor, katup ekspansi, dan evaporator dengan fluida kerja berupa refrigeran [3]. Pada penelitian ini sistem heat pump yang dipakai menggunakan sistem refrigerasi kompresi uap. Dimana kompresor akan mengkompresi refrigeran agar tekanan dan temperatur naik sehingga dapat membuang kalor ke lingkungan saat di kondensor, lalu katup ekspansi akan mengekspansi refrigerant agar tekanan dan temperatur turun sehingga dapat menyerap kalor dari lingkungan sekitar yang akan dikondisikan, lalu kembali kompresor dan begitu siklus yang berlangsung seterusnya.

Siklus refrigerasi kompresi uap merupakan suatu sistem yang memanfaatkan aliran perpindahan kalor melalui refrigerant. Proses dari kompresi uap seperti Gambar 1 dibawah adalah:

1. Proses kompresi (1-2)

2. Proses kondensasi (2-3)

3. Proses ekspansi (3-4)

4. Proses evaporasi (4-1)

Seluruh proses siklus refrigerasi di atas diatas dapat ditelusuri dengan menggunakan diagram tekanan-entalpi (pressure-entalphy, $p$ - $h$ ) yang dikenal dengan diagram Mollier [3].

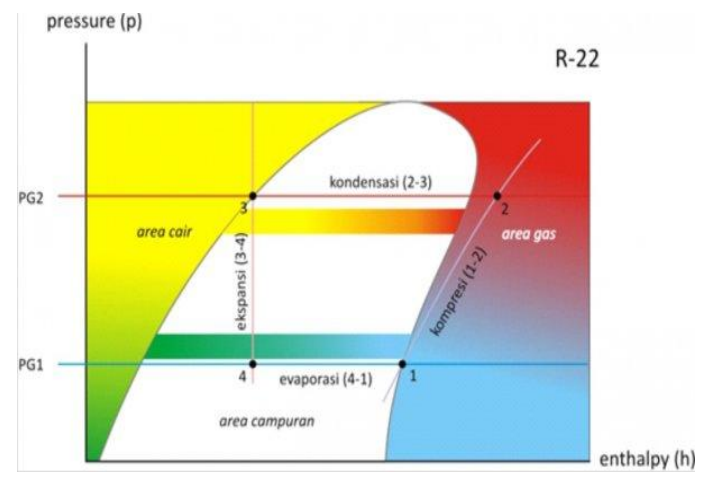

Gambar 1.Siklus pada Mollier diagram

\section{Perhitungan COP}

COP adalah perbandingan kalor yang diserap oleh evaporator (proses evaporasi) dari lingkungan terhadap kerja yang dilakukan oleh kompresor (proses kompresi).

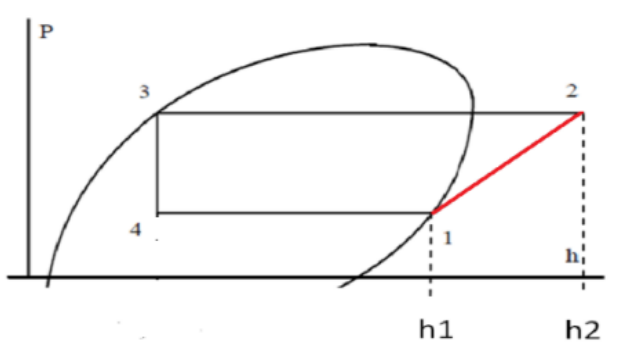

Gambar 2.Proses Kompresi

Pada gambar 2 diatas menunjukkan proses kerja yang dilakukan oleh kompresor atau proses kompresi dimana dapat dihitung dengan menggunakan persamaan

Dimana:

$$
\mathrm{W}=\mathrm{h}_{2}-\mathrm{h}_{1}
$$

$\mathrm{W}=$ Kerja yang dilakukan kompresor $(\mathrm{kj} / \mathrm{s})$

$\mathrm{h}_{1}=$ Entalpi masukan kompresor $(\mathrm{kj} / \mathrm{kg})$

$\mathrm{h}_{2}=$ Entalpi keluaran kompresor $(\mathrm{kj} / \mathrm{kg})$

Untuk perhitungan pada proses evaporasi, refrigerant akan berubah fasa dari fasacampuran (cair-uap) menjadi fasa uap jenuh. Kalor yang diserap di evaporator seperti terlihat pada Gambar. 3 di bawah.

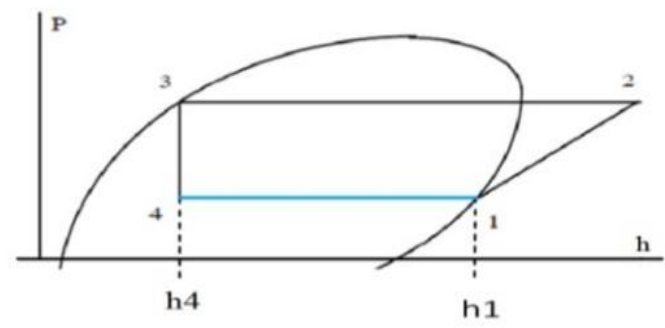

Gambar 3. Proses Evaporasi

Dimana:

$$
\mathrm{Qe}=\mathrm{h} 1-\mathrm{h} 4
$$

Qe $=$ Kalor yang diserap evaporator $(\mathrm{kj} / \mathrm{s})$

$\mathrm{h}_{1}=$ Entalpi keluaran Evaporator $(\mathrm{kj} / \mathrm{kg})$

$\mathrm{h}_{2}=$ Entalpi masukan Evaporator $(\mathrm{kj} / \mathrm{kg})$

Berdasarkan perhitungan diatas maka akan didapat prestasi COP didapat dari perbandingan antara efek refrigerasi dengan kerja kompresi.

Untuk menghitung besarnya COP dapat digunakan persamaan sebagai berikut:

$$
\mathrm{COP}_{\text {actual }}=\frac{Q e\left(\frac{k J}{s}\right)}{W\left(\frac{k J}{s}\right)}
$$

\section{Perhitungan COP Carnot}

$\mathrm{COP}_{\text {carnot }}$ adalah perbandingan temperatur evaporasi dibandingkan dengan selisih temperatur 
kondensasi dan evaporasi. Satuan temperatur yang digunakan dalam rumus $\mathrm{COP}_{\text {carnot }}$ adalah Kelvin.

$$
\mathrm{COP}_{\text {carnot }}=\frac{T \text { evap }}{T \text { konden }- \text { Tevap }}
$$

Dimana:

Tevap = temperatur Evaporasi $(\mathrm{K})$

$\mathrm{T}$ konden $=$ Temperatur Kondensasi $(\mathrm{K})$

\section{Efisiensi Heat Pump}

Efisiensi heat pump adalah perbandingan antara COP dengan COP carnot.

$$
\text { Efisiensi }=\frac{C O P}{\text { COP carnot }}
$$

\section{METODE}

Metode yang dilakukan dalam penelitian ini menitikberatkan pada pengambilan data-data pengukuran yang valid dan baik, hal yang perlu diperhatikan sebelum melakukan pengambilan data adalah memastikan alat ukur yang akan dignakan sudah terkalibrasi dengan baik. Tujuannya adalah agar kesalahan-kesalahan pada pengukuran dan pembacaan pada saat pengambilan data dapat dikurangi. lain:

Adapun data-data yang akan diambil antara

1. Tekanan Discharge Line

2. Tekanan Suction Line

3. Temperatur Masuk Kompresor

4. Temperatur Keluar Kompresor

5. Temperatur Masuk Evaporator

6. Temperatur Keluar Evaporator

7. Temperatur Masuk Kondensor

8. Temperatur Keluar Kondensor

9. Temperatur Masuk Heat Exchanger (gas)

10. Temperatur Keluar Heat Exchanger (gas )

11. Temperatur Keluar Heat Exchanger (liquid)

12. Temperatur Keluar Heat Exchanger (liquid)

13. Temperatur Lingkungan

14. Arus dan Tegangan Listrik

Adapun alat dan bahan dalam pembuatan heat pump ini antara lain:
a. Kompresor $1 \mathrm{PK}$
b. Kondensor
c. Kompresor
d. Four way reversing valveSTF 0101G Danfos
e. Heat Exchanger
f. Kondenser plus
g. Liquid receiver
h. Filter dryer
i. Sight glass
j. TXV
k. Pipa Kapiler
1. Pipa tembaga $1 / 4$ in, dan $1 / 2$ in

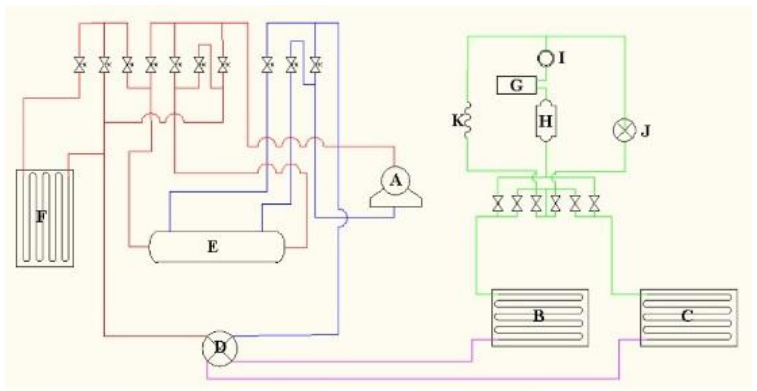

Gambar 4. Diagram Pemipaan Heat Pump

Pada Gambar 4 diatas pemasangan heat exchanger ditempatkan pada keluaran evaporator (suction line) dan masukan kompresor (discharge line). Sedangkan alat ukur yang digunakan untuk pengukuran variable pada penelitian iniadalah sebagai berikut :

a. Untuk pengukuran temperatur menggunakan data akuisisi (Arduino UNO, Sensor LM35,LABview)

b. Untuk pengukuran tekanan: menggunakan High and low pressure gauge

c. Untuk pengukuran arus listrik ampere meter

d. Untuk pengukuran tegangan listrik menggunakan volt meter

Langkah-langkah yang harus dilakukan sebelum pengambilan data adalah sebagai berikut :

a. Pastikan semua alat ukur terpasang baik

b. Kalibrasi alat ukur yang akan digunakan

c. Sebelum sistem dihidupkan, data diukur terlebih dahulu

d. Menghidupkan sistem heat pump

e. Ambil semua data setiap 3 menit 


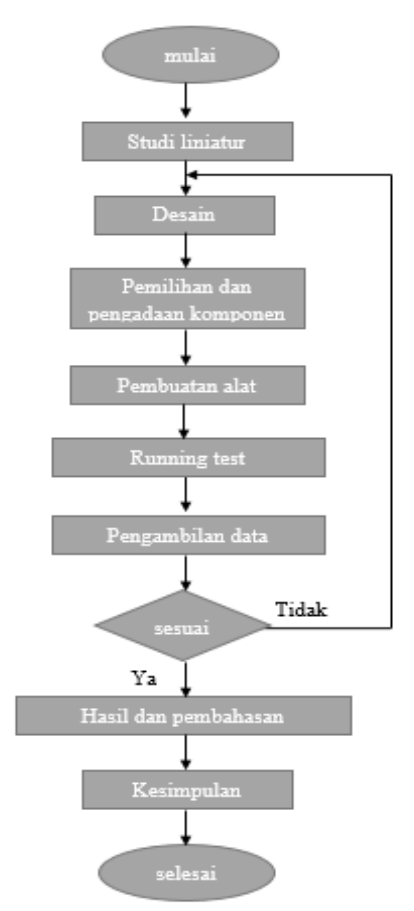

Gambar 5. Alur Penelitian

\section{HASIL DAN PEMBAHASAN}

Untuk dapat mengetahui karakteristik heat pump maka setelah dilakukan pengukuran atau pengambilan data setiap 3 menit sekali selama 45 menit ketika menggunakan heat exchangerdantidak menggunakan heat exchanger.

\section{Perhitungan Coefficient Of Performance (COP) Tanpa Heat Exchanger}

Dari data yang didapatkan temperatur evaporator $=-7^{\circ} \mathrm{C}$ dan temperatur kondensor $14^{\circ} \mathrm{C}$ maka perhitungan nilai COP seperti terlihat pada diagram Moller dibawah pada gambar 6. sebagai berikut :

$\mathrm{qe}=257 \mathrm{~kJ} / \mathrm{kg}$

$\mathrm{W}=62 \mathrm{~kJ} / \mathrm{kg}$

$\mathrm{COP}=\mathrm{qe} / \mathrm{W}$

$$
\begin{aligned}
& =257 \mathrm{~kJ} / \mathrm{kg} / 62 \mathrm{~kJ} / \mathrm{kg} \\
& =4.1
\end{aligned}
$$

Sehingga nilai COP sistem heat pump tanpa menggunakan heat exchanger adalah sebesar 4,1

Sedangkan nilai COPcarnot adalah

Tevap $=-7+273=266 \mathrm{~K}$

Tkonden $=41+273=314 \mathrm{~K}$

$$
\begin{aligned}
\text { COPcarnot } & =\frac{-7+273}{(41+273)-(-7+273)}= \\
& =\frac{266}{(48)}=5,5
\end{aligned}
$$

Sehingga nilai COP sistem heat pump tanpa menggunakan heat exchanger adalah sebesar 5,5 Sehingga efisiensi system heat pump bisa dihitung Efisiensi $=\frac{\text { COP }}{\text { COP carnot }}$ COPactual $=4.1$ COPcarnot $=5,5$

$$
\text { Efisiensi }=\frac{4.1}{5,5} \times 100=0.74=74
$$

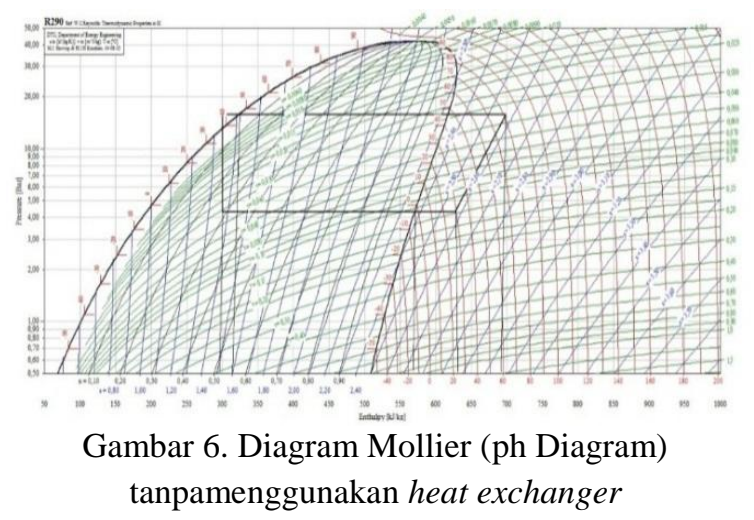

\section{Perhitungan Coefficient Of Performance (COP) Dengan Heat Exchanger}

Dari data yang didapatkan temperatur evaporator $=-2^{\circ} \mathrm{C}$ dan temperatur kondensor $46^{\circ} \mathrm{C}$ kita dapat melakukan perhitungan $\mathrm{COP}$ melalui diagram Mollier seperti gambar 7. Dibawah, sebagai berikut :

qe $=330 \mathrm{~kJ} / \mathrm{kg}$

$\mathrm{W}=68 \mathrm{~kJ} / \mathrm{kg}$

$$
\begin{aligned}
\mathrm{COP} & =\text { qe } / \mathrm{W} \\
& =330 \mathrm{~kJ} / \mathrm{kg} / 68 \mathrm{~kJ} / \mathrm{kg} \\
& =4.8
\end{aligned}
$$

Sehingga nilai COP sistem heat pump dengan menggunakan heat exchanger adalah sebesar 4,8 Sedangkan nilai COPcarnot adalah:

Tevap $=-2+273=271 \mathrm{~K}$

Tkonden $=46+273=319 \mathrm{~K}$

$$
\begin{aligned}
\text { COPcarnot } & =\frac{-2+273}{(46+273)-(-2+273)}= \\
& =\frac{271}{(48)}=5,6
\end{aligned}
$$

Sehingga nilai COP sistem heat pump dengan menggunakan heat exchanger adalah sebesar 5,6 Sehingga efisiensi system heat pump bisa dihitung Efisiensi $=\frac{C O P}{\text { COP } \text { carnot }}$

COPactual $=4.8$

COPcarnot $=5,6$

Efisiensi $=\frac{4.8}{5,6} \times 100=0.85=85 \%$ 


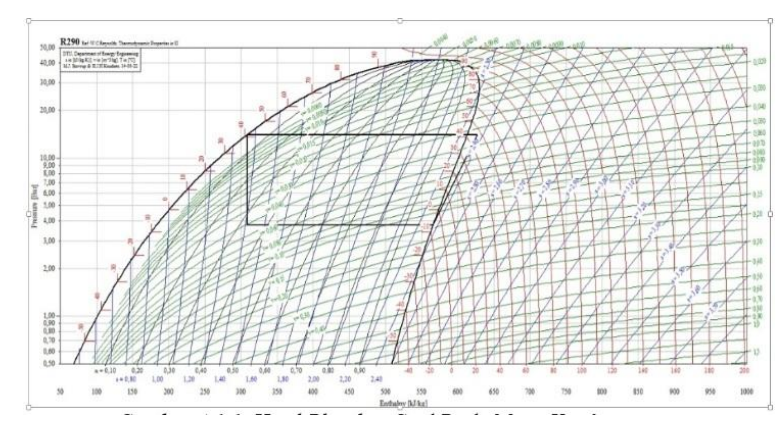

Gambar 7. Diagram Mollier (ph Diagram) menggunakan heat exchanger

\section{Perbandingan COP}

Melalui pengolahan data dan perhitungan dilakukan maka didapatkan nilai COP tertinggi pada heat pump yang menggunakan COP sebesar 5,6 sedangkan COP heat pump tanpa menggunakan heat exchanger tertinggi sebesar 4,6.

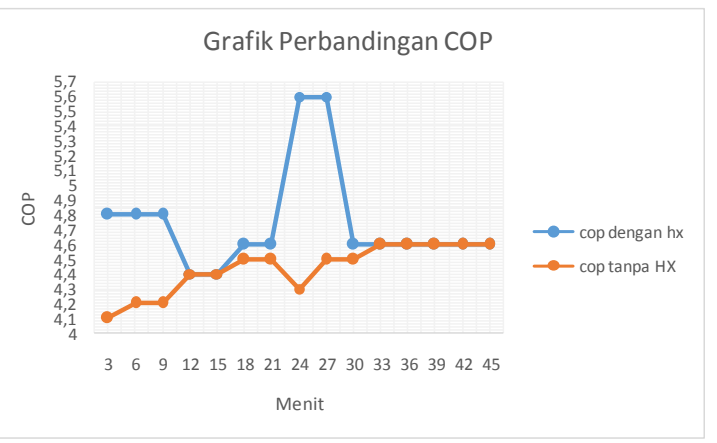

Gambar 8. Grafik perbandingan COP

Dari gambar 8. diatas terlihat dalam grafik untuk heat pump yang menggunakan heat exchanger nilai COP tertinggi sebesar 5,6 pada menit ke-24 dan menit ke-27sedangkan nilai COP terendah sebesar4,4 pada menit ke-12 dan menit ke-15. Untuk nilai COP tertinggi ini dikarenakan tekanan suction sebesar 29 Psi dan tekanan discharge sebesar 220 psi, sedangkan temperatur evaporator sebesar $4,8^{\circ} \mathrm{C}$ dan temperatur kondensor sebesar $73,1^{\circ} \mathrm{C}$.

Untuk nilai COP terendah dikarenakan tekanan suction sebesar 48 Psi dan tekanan discharge sebesar 220 psi, sedangkan temperatur evaporator sebesar 3,9 ${ }^{\circ} \mathrm{C}$ dan temperatur kondensor sebesar $71,2^{\circ} \mathrm{C}$. Sedangkan heat pump tanpa menggunakan heat exchanger nilai COP tertinggi sebesar 4,6 pada menit ke-33, menit ke-36, menit ke-39, menit ke-42, dan menit ke-45, sedangkan nilai COP terendah 4,1 pada menit ke-3.

Untuk nilai COP tertinggi pada heat pump tanpa mengunakan heat exchangerini dikarenakan tekanan suction sebesar 35 Psi dan tekanan discharge sebesar 160 psi, sedangkan temperatur evaporator sebesar $17,3{ }^{\circ} \mathrm{C}$ dan temperatur kondensor sebesar $65,3^{\circ} \mathrm{C}$. Untuk nilai COP terendah pada heat pump tanpa mengunakan heat exchanger ini dikarenakan tekanan suction sebesar 40 Psi dan tekanan discharge sebesar 190 psi, sedangkan temperatur evaporator sebesar $9,8{ }^{\circ} \mathrm{C}$ dan temperatur kondensor sebesar $64,3^{\circ} \mathrm{C}$.

\section{Perbandingan Efisiensi}

Efisiensi sistem heat pump dihitung berdasarkan nilai COP dan COPcarnot dari data yang sudah diambil.Pada gambar 9, dibawah terlihat grafik perbandingan efisiensi heat pump dengan menggunakan heat exchanger dan tanpa menggunakan heat exchanger.

Terlihat pada grafik diatas bahwa efisiensi tertinggi untuk heat pump adalah sebesar 90,3\% dan efisiensi terendah sebesar $74,5 \%$. Untuk efisiensi heat pump yang menggunakan heat exchanger tertinggi sebesar 90,5\% terjadi pada menit ke-24 dan menit ke-27 dan terendah sebesar Sedangkan efisiensi terendah sebesar $80 \%$ terjadi pada menit ke12 dan menit ke-15.

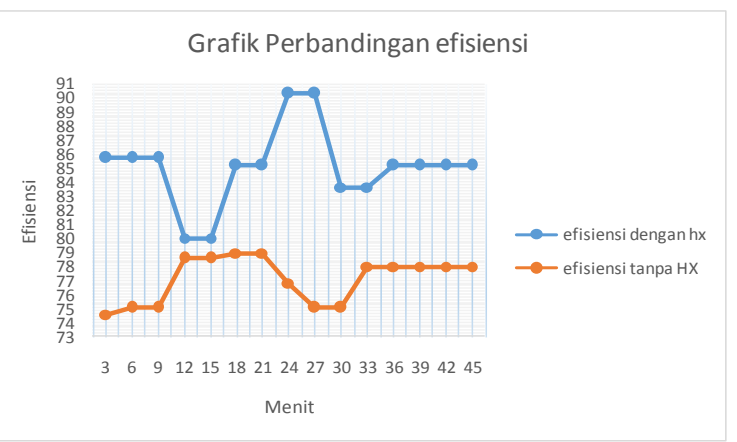

Gambar 9. Grafik perbandingan Efisiensi

Untuk nilai efisiensi tertinggi pada heat pump yang menggunakan heat exchangerini dikarenakan COP heat pump sebesar 5,6 dan COP carnot sebesar 6,2 . Untuk nilai efisiensi terendah pada heat pump yang menggunakan heat exchanger ini dikarenakan COP heat pump sebesar 4,8 dan COP carnot sebesar 5,6. Untuk efisiensi heat pump tanpa menggunakan heat exchanger tertinggi sebesar 78,95\% terjadi pada menit ke-18 dan menit ke-21 dan terendah sebesar Sedangkan efisiensi terendah sebesar $74,55 \%$ terjadi pada menit ke-3.

Untuk nilai efisiensi tertinggi pada heat pump tanpa menggunakan heat exchanger ini dikarenakan COP heat pump sebesar 4,5 dan COP carnot sebesar 5,7. Untuk nilai efisiensi terendah pada heat pump yang menggunakan heat exchanger ini dikarenakan COP heat pump sebesar 4,1 dan COP carnot 5,5. 


\section{KESIMPULAN}

Kesimpulan dari data pengukuran yang sudah dianalisa pada heat pump yaitu:

1. Nilai COP dari data dan hasil perhitungan didapatkan bahwa nilai COP tertinggi pada heat pump yang menggunakan heat exchanger adalah 4,8 sedangkan heat pumpyang tidak menggunakan heat exchanger adalah 4,1.

2. Nilai efisiensi heat pump yang tidak menggunakan heat exchanger sebesar 74,5\% sedangkan yang menggunakan heat exchanger sebesar 90,3\%, sehingga effisiensi pada heat рump dengan menggunakan heat exchanger mempengaruhi nilai efisiensi. Dimana sistem yang menggunakan heat exchanger nilai effisiensi menjadi lebih tinggi.

3. Pada data hasil pengukuran sistemheat pump yang menggunakanheat exchanger temperatur refrigeran masuk kedalam kompresor lebih tinggi dibandingkan dengan yang menggunakan heat exchanger karena didalam heatexchanger terdapat perpindahan kalor panas sehingga temperatur yang masuk kedalam kompresor mencapai $33^{\circ} \mathrm{C}$ sedangkan pada sistem yang tidak menggunakan heat exchanger, refrijeran masuk kompresor mencapai $28,5^{\circ} \mathrm{C}$.

4. Temperatur evaporator terendah dari heat pump yang menggunakan heat exchanger sebesar 3,1 ${ }^{\circ} \mathrm{C}$ sedangkan heat pump yang tidak menggunakan heat exchanger sebesar $4,4{ }^{\circ} \mathrm{C}$

5. Temperatur kondensor tertinggi dari heat pump yang menggunakan heat exchanger sebesar 73,1 ${ }^{\circ} \mathrm{C}$ sedangkan heat pump yang tidak menggunakan heat exchanger sebesar $66,9^{\circ} \mathrm{C}$.

\section{DAFTAR PUSTAKA}

1. Wilbert F. Stracker, Jerold W. Jones, Supratman Hara, 1989. Rerigerasi dan Pengkondisian Udara, Bandung.

2. Yunxiang $\mathrm{Li}$, Jianlin $\mathrm{Yu}$. Theoretical analysis on optimal configurations of heat exchanger and compressor in a two-stage compression air source heat pump system. Appl Therm Eng. 2015 Nov 27;4311(15)01395-2

3. Dossat, Roy J. 1981. Principles of Refrigeration Second Edition SI Version.Canada: John Wiley and Sons, Inc.

4. Hakkaki-Fard A, Aidoun Z, Ouzzane M. Applying refrigerant mixtures with thermal glide in cold climate air-source heat pumps. Appl Therm Eng. 2014 Jan 25;62(2):714-22.

5. Waheed MA, Oni AO, Adejuyigbe SB, Adewumi BA, Fadare DA. Performance enhancement of vapor recompression heat pump. Appl Energy. 2014 Feb;114:69-79.
6. Xu X, Hwang Y, Radermacher R. Transient and steady-state experimental investigation of flash tank vapor injection heat pump cycle control strategy. Int J Refrig. 2011 Dec;34(8):1922-33. 